\title{
FEASIBILITY STUDY BENDUNGAN POH SANTEN DI KABUPATEN JEMBRANA
}

\author{
Ketut Nuraga dan I Gusti Lanang Bagus Eratodi \\ Program Studi Teknik Sipil FTI Universitas Pendidikan Nasional \\ Email: ketutnuraga@undiknas.ac.id
}

\begin{abstract}
ABSTRAK
Pembangunan sarana penyediaan air baku bagi Kabupaten Jembrana merupakan salah satu kebutuhan yang utama bagi kelangsungan hidup masyarakat di daerah tersebut. Sarana penyediaan air baku berupa bendungan sebagai tempat tampungan air merupakan suatu alternatif dalam mengatasi masalah pemenuhan kebutuhan air irigasi dan air bersih didaerah tersebut. Pada studi-studi tentang ketersediaan air baik air permukaan maupun bawah permukaan dengan tingkat kebutuhan air penduduk di Kabupaten Jembrana yang semakin meningkat, maka telah direkomendasikan untuk melakukan kajian-kajian teknis tentang upaya-upaya penyediaan air baku terutama dengan membangun bendungan. Salah satu studi yang telah direkomendasikan adalah melakukan studi pendahuluan berupa studi kelayakan Bendungan Poh Santen di daerah aliran sungai (DAS) Tukad Pergung di Kecamatan Medoyo. Dalam studi ini, desain awal bendungan Poh Santen dipilih konstruksi Bendungan Tipe Urugan Inti Vertikal dengan material urugan random sesuai dengan ketersediaan jenis material di lokasi studi. Tinggi bendungan $32 \mathrm{~m}$ dan tampungan total sebesar 1,272x106 $\mathrm{m}^{3}$. Pemanfaatan air bendungan Poh Santen untuk memenuhi kebutuhan air irigasi seluas 269 ha dan memenuhi kebutuhan air bersih penduduk dengan debit rencana sebesar $0,142 \mathrm{~m}^{3} / \mathrm{dt}$. Analisis kelayakan didapat hasil bendungan Poh Santen dinyatakan sangat layak untuk dilajutkan pada tahap Detail Desain (IRR $>12 \%$ dan $B C R>1)$
\end{abstract}

Kata kunci: bendungan, tampungan, air irigasi, air bersih, kelayakan teknis

\begin{abstract}
The construction of raw water supply facilities for Jembrana Regency is one of the main needs for the survival of the people in the area. Means of supplying raw water in the form of dams as water reservoirs are an alternative in overcoming the problem of meeting the needs of irrigation water and clean water in the area. In studies of the availability of water both surface and subsurface water with the increasing level of water needs of the population in Jembrana Regency, it has been recommended to conduct technical studies on efforts to provide raw water, especially by building dams. One study that has been recommended is a preliminary study in the form of a feasibility study of the Poh Santen Dam in the Tukad Pergung watershed in Medoyo District. In this study, the initial design of the Poh Santen dam was chosen by the construction of a Vertical Core Urugan Dam type with a random Urugan material according to the availability of material types at the study site. The dam is $32 \mathrm{~m}$ high and the total reservoir is $1,272 \times 106$ m3. Utilization of Poh Santen dam water to meet irrigation water needs covering an area of 269 ha and meet the population's clean water needs with a planned discharge of $0.142 \mathrm{m3} / \mathrm{sec}$. The feasibility analysis shows that the results of the Poh Santen dam are declared to be very feasible to be continued at the Design Detail stage (IRR> $12 \%$ and $B C R>1)$
\end{abstract}

Keywords: dams, reservoirs, irrigation water, clean water, technical feasibility

\section{PENDAHULUAN}

Sumber daya air sebagai salah satu sumber daya alam yang sangat vital perlu dimanfaatkan dan ditangani secara seksama. Penggunaan air untuk irigasi dan air minum merupakan satu diantara berbagai alternatif pemanfaatan air. Di Indonesia penggunaan air terbesar adalah untuk keperluan irigasi dan air minum.
Provinsi Bali dengan luas wilayah 6.142,24 $\mathrm{km}^{2}$ memiliki 247 daerah aliran sungai (DAS) dan hanya sebagian dari sejumlah sungai yang ada di Bali merupakan potensi sumber air untuk pengembangan irigasi, air minum, industri dan sebagainya. Akibat perbedaan kondisi topografi dan geologi masing-masing kabupaten di Provinsi Bali menyebabkan ketersediaan air di pulau Bali menjadi tidak merata, dimana daerah Bali Barat dan Tengah mempunyai potensi air 
berlebih, sedangkan di bagian Timur dan sebagian Utara kekurangan air. Kondisi demikian mengharuskan adanya pola pengembangan sumber air melalui pembangunan prasarana penyediaan air baku yang memenuhi standar teknis, ekonomis dan lingkungan.

Kondisi pelayanan air bersih di Kabupaten Jembrana memiliki tingkat pelayanan yang masih rendah dan belum merata. PDAM Kabupaten Jembrana dalam melakukan pengadaan air bersih dengan memanfaatkan air sumur dalam dengan kapasitas $139 \mathrm{lt} / \mathrm{dt}$, sedangkan kebutuhan sebesar 159 It/dt. Instalasi pelayanan air bersih yang dikelola PDAM dengan tingkat pelayanan $\pm 24,43 \%$ dari seluruh penduduk di Kabupaten Jembrana. Dengan demikian masih sebagian besar penduduk yang belum tertangani oleh pelayanan air bersih dari PDAM terutama untuk masyarakat pedesaan.

Pembangunan sarana penyediaan air baku bagi Kabupaten Jembrana merupakan salah satu kebutuhan yang utama bagi kelangsungan hidup masyarakat di daerah tersebut. Tersedianya sarana penyediaan air baku yang memadai baik dari segi kuantitas, kualitas dan kontinuitas, sedikitnya akan mengurangi permasalahan pemenuhan kebutuhan air irigasi dan air bersih di daerah tersebut. Sarana penyediaan air baku berupa bendungan sebagai tempat tampungan air merupakan suatu alternatif dalam mengatasi masalah pemenuhan kebutuhan air irigasi dan air bersih didaerah tersebut. Hal ini mengingat sumber air permukaan (air sungai) memiliki fluktuasi debit antara musim hujan dan musim kemarau yang cukup besar dan belum dimanfaatkan secara maksimal.

Disamping itu pembangunan suatu bendungan juga merupakan suatu usaha konservasi sumber daya air sehingga diharapkan dengan adanya tampungan selain mengurangi degradasi sumber air juga untuk pengendalian/ menghambat air hujan terbuang ke laut. Bendungan merupakan suatu bangunan yang cukup besar dalam artian biaya dan aspek-aspek lain yang ditimbulkannya, sehingga rencana pembangunannya memerlukan pengajian secara mendalam baik dari segi teknis, ekonomi dan lingkungan.

Sejalan dengan uraian tersebut diatas, dengan tetap memperhatikan keterkaitan dan kesinambungan program pengembangan sumber daya air di wilayah Kabupaten Jembrana serta upaya-upaya yang sudah pernah dilaksanakan, maka perlu dilakukan suatu kajian untuk optimasi pemanfaatan dan pengembangan sumber air yang ada agar permasalahan pemenuhan air irigasi dan air bersih dapat tertangani.

Permasalahan pemenuhan kebutuhan air baku untuk air irigasi dan air bersih, saat ini dialami masyarakat Desa Poh Santen, Desa Tegalcangkring, Desa Pergung dan sekitarnya. Kondisi eksisting pemenuhan kebutuhan air (air irigasi dan air bersih) di daerah tersebut dengan memanfaatkan aliran air Tukad Pergung. Akan tetapi akibat menurunnya debit air Tukad Pergung mengakibatkan masyarakat mengalami kesulitan dalam memenuhi kebutuhan air irigasi dan air bersih terutama pada musim kemarau. Fluktuasi debit air Tukad Pergung cukup besar antara musim hujan dan musim kemarau, dimana pada musim kemarau debit air sangat kecil sebesar $0,30 \mathrm{~m}^{3} / \mathrm{dt}$ dan pada musim hujan sebesar $350 \mathrm{~m}^{3} / \mathrm{dt}$ yang terbuang ke laut.

Secara umum maksud dari kegiatan Feasibility Study Bendungan Poh Santen di Kabupaten Jembrana adalah untuk memenuhi kebutuhan penyediaan air baku masyarakat dengan memanfaatkan potensi 
sumber air Tukad Pergung secara optimal, melalui pengkajian secara mendalam baik dari segi teknis, ekonomi dan lingkungan.

Tujuannya adalah mendapatkan suatu nilai kelayakan terhadap rencana pembangunan Bendungan Poh Santen yaitu layak teknik, ekonomi dan lingkungan sebelum melangkah ke tahap perencanaan selanjutnya.

\section{METODE}

Lokasi kegiatan Feasibility Study Bendungan Poh Santen berlokasi di Desa Poh Santen Kecamatan Mendoyo Kabupaten Jembrana. Peta lokasi studi dapat dilihat pada Gambar 1.

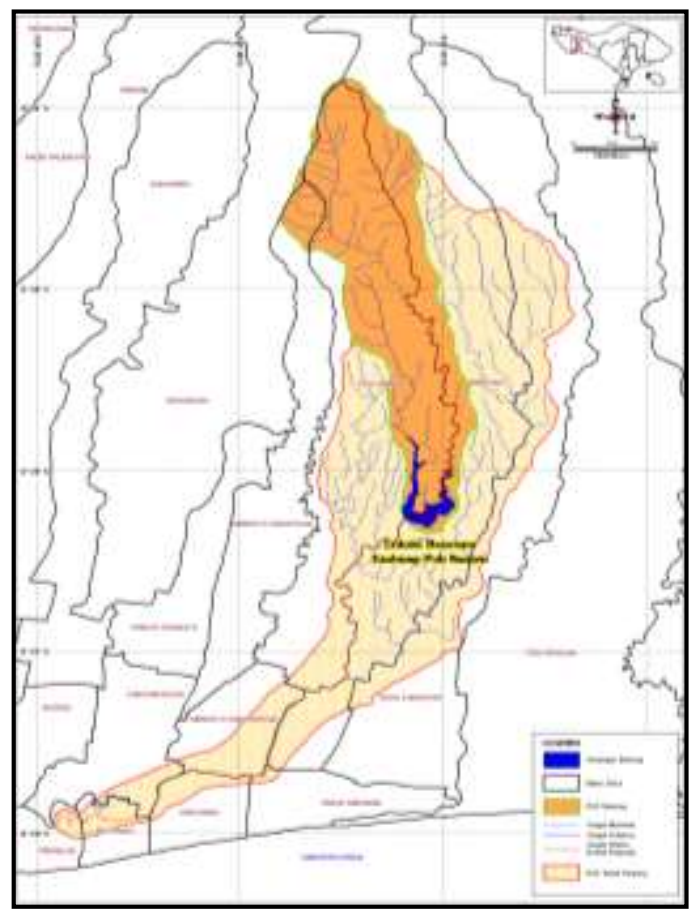

Gambar 1. Peta Lokasi Studi

\section{LANDASAN TEORI}

Untuk memperoleh data hujan rerata wilayah digunakan metode Poligon Thiessen (Soemarto, 1987:32) dengan menggunakan Persamaan 1.

$$
\overline{\mathrm{d}}=\frac{\mathrm{A}_{1} \cdot \mathrm{d}_{1}+\mathrm{A}_{2} \cdot \mathrm{d}_{2}+\ldots \ldots \ldots+\mathrm{An} \cdot \mathrm{dn}}{\mathrm{A}}
$$

$$
\begin{aligned}
\overline{\mathrm{d}}= & \text { tinggi curah hujan rata-rata } \\
& \text { areal }(\mathrm{mm}) \\
\mathrm{d}_{1,2, \ldots \mathrm{dn}=} & \begin{array}{l}
\text { tinggi curah hujan di satsiun } \\
\text { hujan } 1,2, \ldots ., \mathrm{n}(\mathrm{mm}) .
\end{array} \\
\mathrm{A}_{1,2 . . \mathrm{An}=} & \text { luas daerah pengaruh stasiun } \\
& \text { hujan } 1,2, \ldots ., \mathrm{n}(\mathrm{mm}) . \\
\mathrm{A} \quad= & \text { luas total DAS }\left(\mathrm{km}^{2}\right)
\end{aligned}
$$

Kebutuhan air irigasi (irrigation water requirement) dapat dihitung berdasarkan pada kondisi yang terbaik, dimana diperhitungkan adanya tinggi genangan minimum di sawah dan berdasarkan pada neraca (imbangan) air mingguan (Sudjarwadi, 1987:17). Departemen Pekerjaan Umum (1986), memberikan rumusan perhitungan kebutuhan air irigasi untuk padi dan palawija adalah sebagai berikut (KP-01, 1986:32). Perhitungan KAT padi dan palawija menggunakan Persamaan 2 dan Persamaan 3.

$$
\begin{aligned}
& \text { KAT Padi }=\frac{\text { Kt.Eto }+\mathrm{P}+\mathrm{GAL}-\mathrm{HE}}{\mathrm{EI}} \\
& \text { KAT Pal }=\frac{\text { Kt.Eto }-\mathrm{HE}}{\mathrm{EI}}
\end{aligned}
$$

dengan:

$$
\text { KAT Pd = kebutuhan air padi (lt/dt/ha) }
$$$$
\text { KAT Pal = kebutuhan air palawija }
$$
(lt/dt/ha)

Kt.Eto = evapotranspirasi tanaman (Etc) $(\mathrm{mm} /$ hari)

$\mathrm{Kt}=$ koefisien tanaman

$\mathrm{P} \quad=$ perkolasi $(\mathrm{mm} /$ hari)

$\mathrm{HE} \quad=$ hujan efektif $(\mathrm{mm} /$ hari $)$

GAL = genangan pengganti air (mm/hari)

$\mathrm{EI} \quad=$ efisiensi irigasi $(\%)$

Pada studi ini perhitungan debit andalan memakai metode tahun dasar perencanaan (basic year). Penentuan debit andalan (dependable discharge) menggunakan metode ini antara lain dengan menentukan suatu tahun tertentu sebagai tahun dasar perencanaan, dengan Persamaan 4.

dengan: 


$$
Q_{80}=\frac{n}{5}+1
$$

dengan:

$$
\begin{aligned}
Q_{80}= & \text { debit dengan probabilitas } 80 \% \\
& \left(\mathrm{~m}^{3} / \mathrm{dt}\right) \\
\mathrm{n}= & \text { panjang data serial data debit }
\end{aligned}
$$

Curah hujan rancangan adalah curah hujan dengan periode ulang (return period) tertentu. (Imam Subarkah, 1980:57). Periode ulang ditakrifkan sebagai waktu hipotetik dimana hujan atau debit dengan suatu besaran tertentu disamai atau dilampaui sekali dalam jangka waktu tersebut (Sri Harto, 1990:289).

Koefisien pengaliran adalah suatu besaran karakteristik DAS yang tergantung pada keadaan daerah pengaliran (seperti bentuk DAS, topografi, struktur geologi, tata guna lahan) dan karakteristik hujan pada DAS tersebut (Sosrodarsono S,1981:144).

Untuk menghitung hidograf banjir rancangan dengan cara hidrograf satuan perlu diketahui terlebih dahulu sebaran hujan jam-jaman dengan suatu interval tertentu. Hujan jam-jaman adalah hujan yang terdistribusi setiap jam selama waktu konsentrasi hujan (Ditjen Pengairan, 1986:21). Di daerah pengaliran sungai di Indonesia biasanya selang waktu (waktu konsentrasi) terjadinya hujan antara 5-7 jam.

Untuk menghitung besarnya debit banjir perencanaan (design flood) maka harus dicari besarnya curah hujan netto (efektif) berdasarkan besarnya hujan rencana. Curah hujan efektif adalah bagian dari hujan total yang menghasilkan limpasan langsung (Soemarto CD,1987). Bentuk limpasan langsung ini terdiri dari limpasan permukaan (direct run off) dan aliran antara (interflow).

Hidrograf satuan sintetik merupakan teori hidrograf yang dikembangkan untuk menentukan banjir dengan input berupa hujan satuan (1 $\mathrm{mm}$ kedalaman hujan). Hujan dianggap merata diatas daerah aliran sungai.

Hidrograf satuan menunjukkan bagaimana hujan netto ditransformasikan menjadi limpasan langsung di pelepasan (outlet) suatu watersheed. Input hidrograf satuan berupa hujan merata, yaitu berupa hujan dengan intensitas (i) dan dengan durasi tertentu $(T)$ yang terbagi merata di atas “watershed" (CD. Soemarto, 1987:114).

Debit banjir rancangan (design flood) adalah debit banjir yang dipergunakan sebagai dasar untuk merencanakan kemampuan dan ketahanan suatu bangunan pengairan yang akan dibangun pada alur sungai (DPU, Ditjen Pengairan, 1990).

Debit banjir rencana (design flood) adalah debit maksimum yang mungkin terjadi pada suatu sungai dengan peluang kejadian tertentu.

Penelusuran banjir adalah prakiraan hidrograf banjir di suatu titik pada suatu aliran atau bagian sungai yang didasarkan atas pengamatan hidrograf di titik lain. Dasar perhitungan penelusuran banjir (flood routing), menggunakan beberapa data masukan yaitu:

1. Aliran masuk (inflow), adalah aliran yang masuk ke waduk dalam hal ini berupa inflow dari hidrograf banjir

2. Aliran keluar (outflow), adalah aliran yang keluar dari waduk sebagai output dari hitungan penelusuran banjir

3. Tampungan (storage), adalah besarnya volume tampungan waduk, dan biasanya dinyatakan sebagai fungsi kedalaman air atau elevasi muka air.

4. Lengkung kapasitas (capacity curve), adalah hubungan antara elevasi muka air waduk, luas permukaan genangan waduk dan volume tampungan. 
Bendungan pengelak adalah bendungan yang berfungsi sementara untuk mengelakkan banjir pada saat pembangunan tubuh bendungan. Bendungan pengelak berfungsi secara bersama-sama dengan saluran pengelak. Dalam perencanaan bendungan terdapat 2 (dua) bendungan pengelak, yaitu bendungan pengelak hulu (udik) dan bendungan pengelak hilir (Suyono Sosrodarsono, 1981 ; 259).

Terowongan pengelak merupakan saluran tertutup yang berfungsi mengalirkan air agar pada lokasi pembangunan bendungan tidak terdapat air (kering) untuk memudahkan pelaksanaan pekerjaan bendungan utama (main dam). Terowongan pengelak biasanya berbentuk lingkaran yang terbuat dari beton bertulang atau baja pra-cetak. Jadi terowongan pengelak merupakan pipa penyalur air yang melintang horizontal di dasar bendungan dan pembuatannya dengan penggalian secara terbuka (Suyono Sosrodarsono, 1981 ; 236).

Bangunan pelimpah adalah bangunan yang berfungsi untuk melimpahkan air pada saat banjir agar tidak terjadi overtopping pada puncak bendungan. Bangunan pelimpah tipe ini terdiri dari empat bagian utama, yaitu (Sosrodarsono, S., 1981:178): saluran pengarah aliran, saluran pengatur aliran, saluran peluncur dan peredam energi.

Untuk menentukan elevasi mercu bendungan harus diberikan tinggi jagaan (freeboard) yang cukup dan diperhitungkan dari muka air tinggi (high water level, HWL) di waduk . Jagaan (free board) ini berfungsi untuk mencegah agar air tidak meluap ke puncak (crest) tubuh bendungan (overtopping). Untuk itu hendaknya jagaan direncanakan dengan memperhitungkan berbagai faktor hidraulik air di waduk.
Tampungan mati (dead storage) pada suatu waduk dimaksudkan untuk memberi ruang pada waduk untuk sedimen yang masuk. Tampungan ini menentukan umur suatu waduk (lifetime bendungan).

\section{PEMBAHASAN}

Di hilir lokasi rencana Bendungan Poh Santen, aliran Tukad Pergung saat ini dimanfaatkan untuk irigasi dari 2 (dua) daerah irigasi (DI), yaitu Daerah Irigasi Semanggong (129 Ha) dan Daerah Irigasi Pecelengan (164 Ha). Kedua daerah irigasi tersebut merupakan daerah semi teknis. Intensitas tanam hanya bisa 2 kali tanam setahun dengan pola tanam padipadi/palawija.

Pemanfaatan air Bendungan Poh Santen adalah untuk irigasi masing-masing $293 \mathrm{Ha}$ untuk penyediaan air minum bagi masyarakat di sekitar desa-desa di wilayah Kecamatan Mendoyo dan Kecamatan Melaya dan bahkan untuk suplesi ke Kota Negara. Skema rencana pemanfaatan air bendungan dapat dilihat pada Gambar 2.

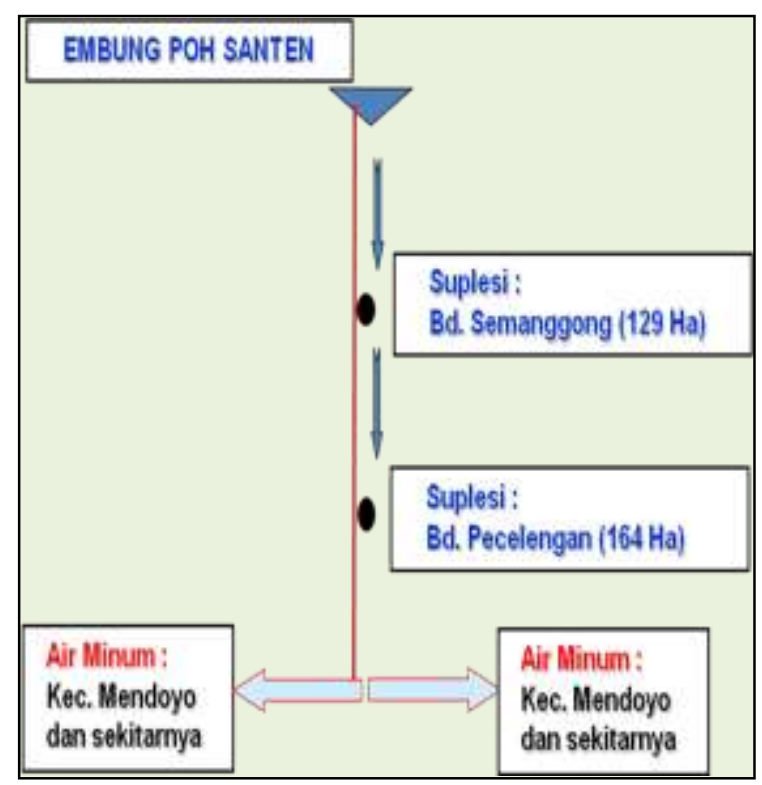

Gambar 2. Skema Rencana Pemanfaatan Air Bendungan

Dalam Feasibility Study perencanaan Bendungan maka diwajibkan menentukan 
beberapa alternatif as untuk mencari suatu hasil perencanaan optimal mencakup beberapa hal sebagai berikut:

1. Panjang tubuh bendungan terpendek.

2. Tampungan yang diperoleh mempunyai volume terbesar

3. Secara geologi diperoleh kondisi struktur tanah paling kuat.

Bebearapa alternatif as Bendungan dapat dilihat pada Gambar 3. Dengan memperhatikan volume tampungan maksimum dan panjang mercu bendungan terpendek, dipilih As Alternatif II, dengan volume tampungan: $1.272 .412,00 \mathrm{~m}^{3}$ dan panjang mercu bendungan $96 \mathrm{~m}$.

Stasiun hujan yang diperhitungkan untuk perencanaan Bendungan Poh Santen adalah sta. Dauh Waru, sta. Poh Santen, dan sta. Tibutanggang. Setelah dilakukan analisis maka perhitungan curah hujan daerah (areal rainfall) dipakai Metode Poligon Thiessen, karena setelah ditarik garis hubung antrara ke tiga stasiun hujan tersebut memenuhi persyaratan Poligon Thiessen. Hasil perhitungan hujan rancangan bendungan Poh Santen dapat dilihat pada Tabel 1.
Perhitungan debit banjir rencana dihitung dengan metode Hidrograf Satuan Nakayasu. Setelah dilakukan analisis debit rancangan didapat hasil seperti Tabel 2. Hasil perhitungan hidrograf banjir rancangan dengan metode hidrograf satuan Nakayasu disajikan pada Gambar 4.

Tabel 1. Analisis Hujan Rancangan Bend. Poh Santen

\begin{tabular}{cccc}
\hline No. & $\begin{array}{c}\text { Kala Ulang, T } \\
\text { (th) }\end{array}$ & G & $\begin{array}{c}\text { Hujan } \\
\text { Rancangan }(\mathrm{mm})\end{array}$ \\
\hline 1 & 2 & 0,013 & 130,83 \\
2 & 5 & 0,845 & 171,96 \\
3 & 10 & 1,273 & 197,89 \\
4 & 20 & 1,573 & 218,44 \\
5 & 25 & 1,723 & 229,50 \\
6 & 50 & 2,011 & 252,29 \\
7 & 100 & 2,268 & 274,45 \\
8 & 200 & 2,502 & 296,42 \\
9 & 1000 & 2,980 & 346,82 \\
\hline
\end{tabular}

Tabel 2. Analisis Debit Rancangan Bend. Poh Santen

\begin{tabular}{ccc}
\hline No. & $\begin{array}{c}\text { Periode Ulang, } \\
\text { T. (th) }\end{array}$ & $\begin{array}{c}\text { Debit Rancangan } \\
\text { (Q) }\left(\mathrm{m}^{3} / \mathrm{dt}\right)\end{array}$ \\
\hline 1 & 10 & 116,543 \\
2 & 25 & 134,998 \\
3 & 100 & 161,246 \\
4 & 1000 & 203,497 \\
5 & PMF & 244,197 \\
\hline
\end{tabular}




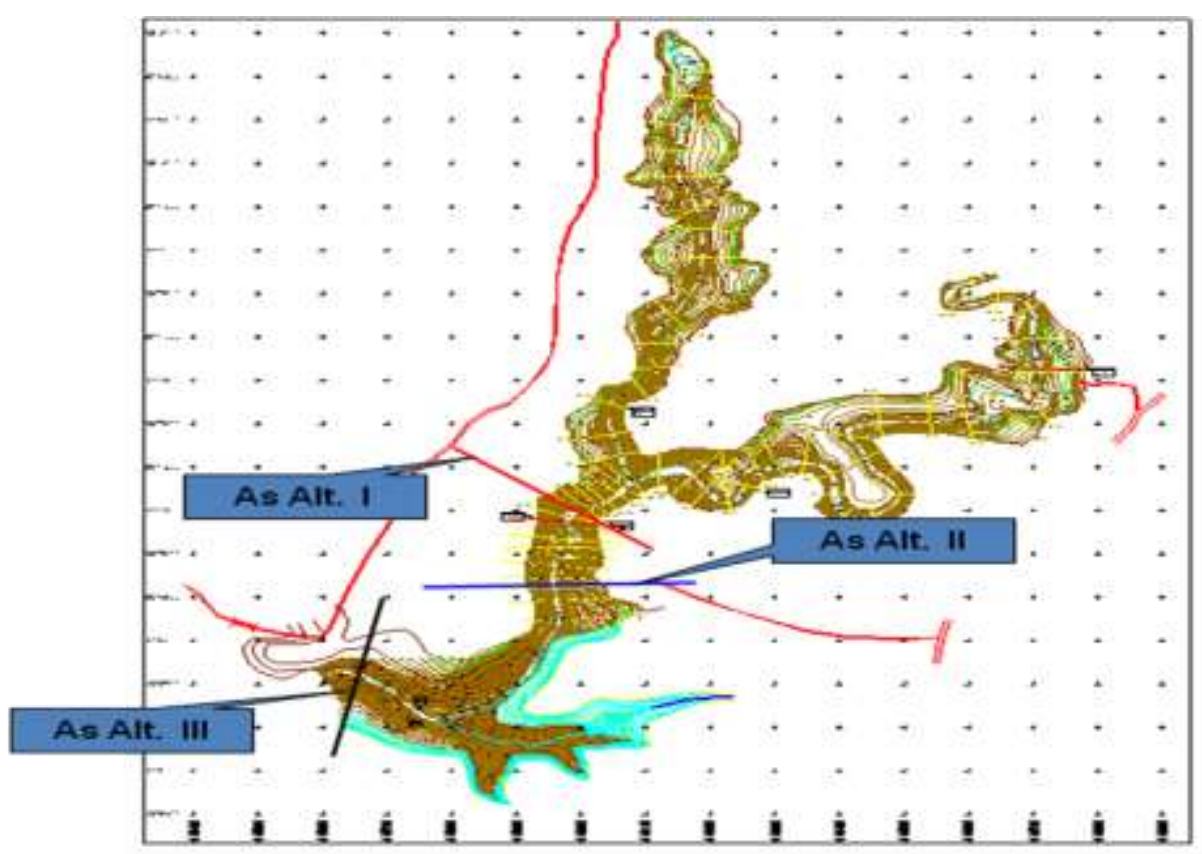

Gambar 3. As Alternatif Bendungan Poh Santen

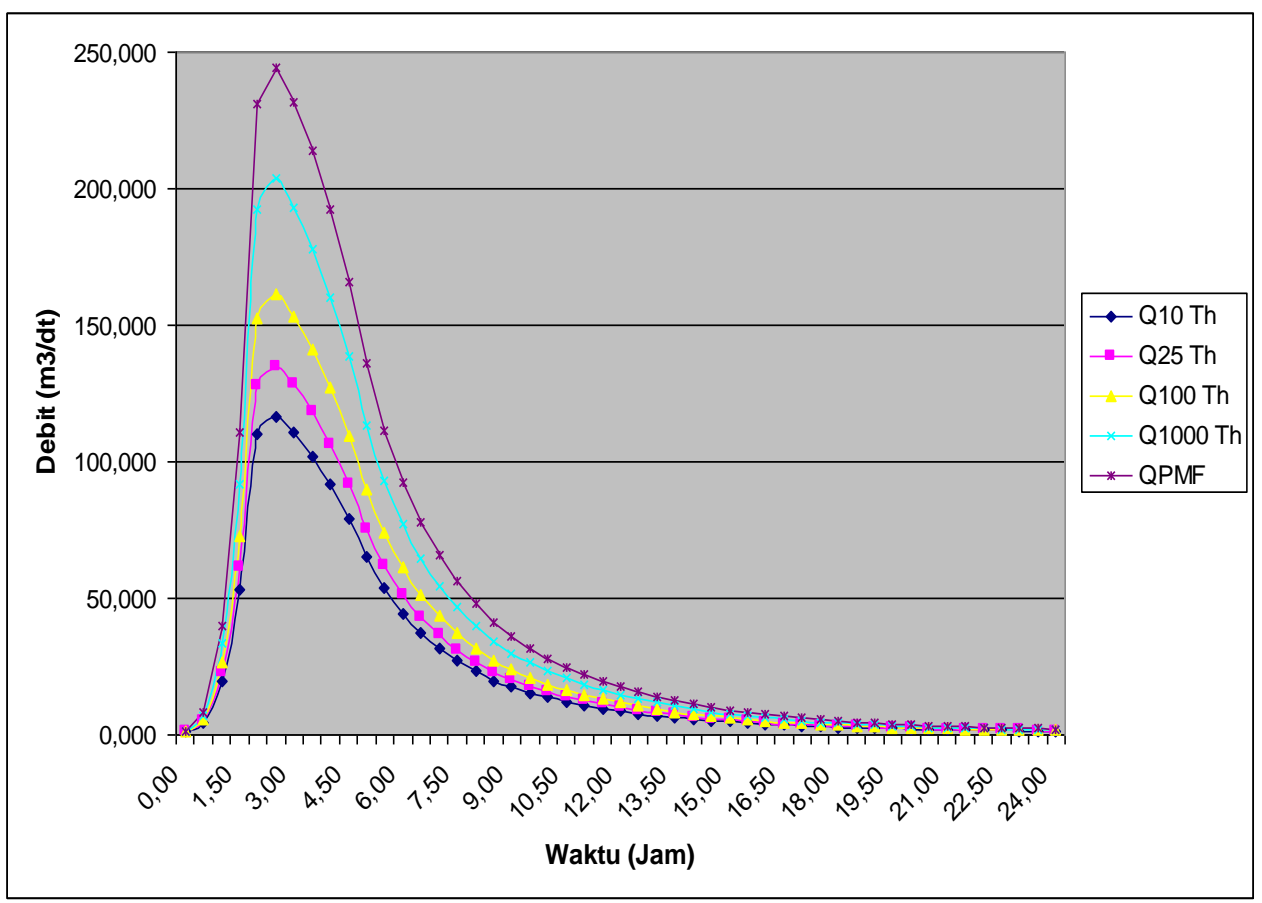

Gambar 4. Hidrograf Banjir Rancangan Bend Poh Santen

Berdasarkan hasil perhitungan laju erosi dan sedimentasi, dapat diketahui bahwa total potensial sedimentasi adalah 170,338 $\mathrm{m}^{3} /$ tahun. Dengan laju sedimentasi tersebut, dengan usia guna waduk selama 75 tahun diperoleh tampungan mati sebesar $12.775,32 \mathrm{~m}^{3}$ pada elevasi $+38,30 \mathrm{~m}$.
Dalam simulasi tampungan waduk ditetapkan sebagai batasan sebagai berikut:

1. Kapasitas tampungan efektif yaitu dari elevasi intake (Low Water Level, LWL) sampai mercu pelimpah (Normal Water Level, NWL). 
2. Kemampuan optimal menyediakan air minum bagi penduduk.

Dengan beberapa trial yang telah dilakukan dari simulasi tampungan maka didapat kondisi optimal manfaat Bendungan Poh Santen sebagai berikut.

1. Tampungan total waduk diperoleh $1.272,412 \times 103 \mathrm{~m}^{3}$ pada elevasi mercu pelimpah $+63,0 \mathrm{~m}$.

2. Tampungan mati (dead storage) dari hasil sedimentasi sebesar 12.775,32 $\mathrm{m}^{3}$ sehingga elevasi intake (LWL) ditetapkan + 38,30 m.

3. Berdasasarkan besarnya tampungan total dan tampungan mati tersebut, diperoleh tampungan efektif sebesar $1.259,637 \times 103 \mathrm{~m}^{3}$.

4. Debit optimal air minum yang bisa disediakan dari waduk sebesar 0,142 $\mathrm{m}^{3} / \mathrm{dt}$.

5. Volume air minimum di waduk adalah $17,363 \times 10^{3} \mathrm{~m}^{3}$ pada el. $+39,10 \mathrm{~m}$ dan kondisi ini masih berada di atas muka air minimum (LWL) yaitu pada elevasi + $38,30 \mathrm{~m}$.

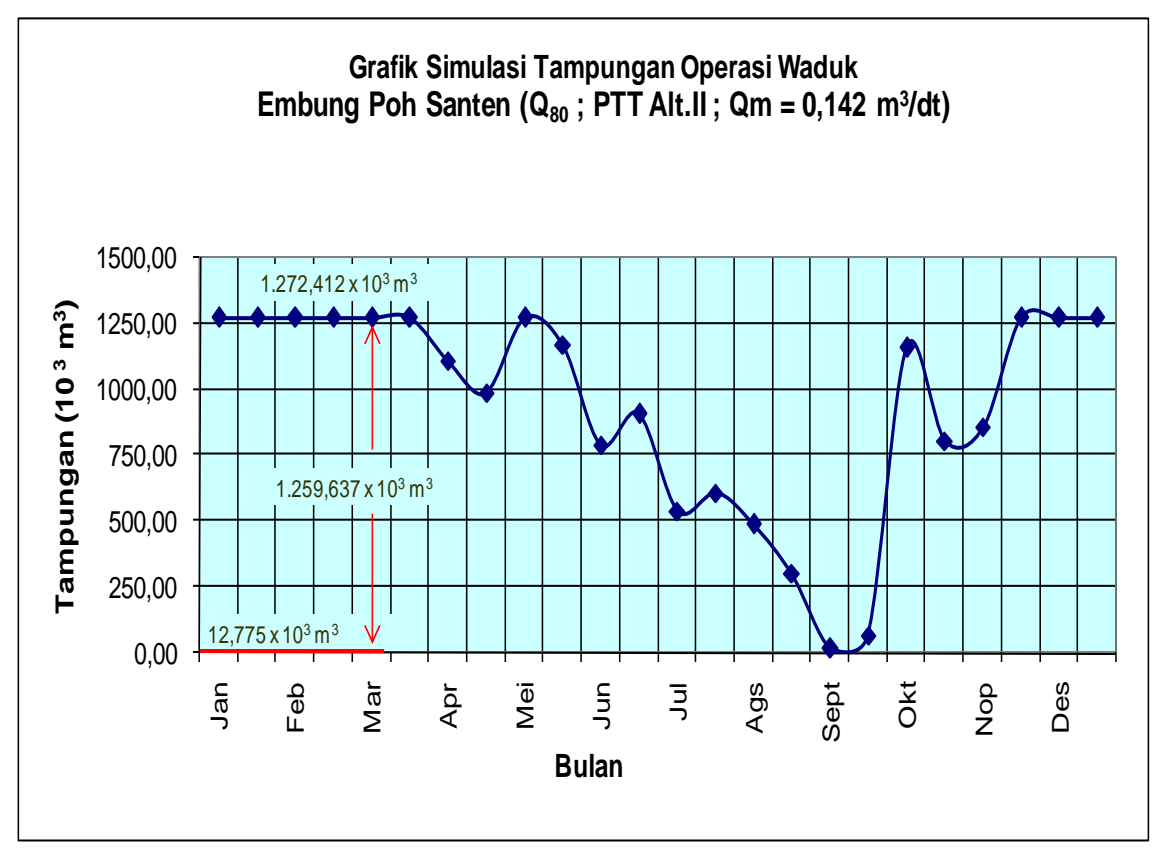

Gambar 5. Grafik Simulasi Waduk Bend. Poh Santen (Sumber : Hasil Perhitungan) 


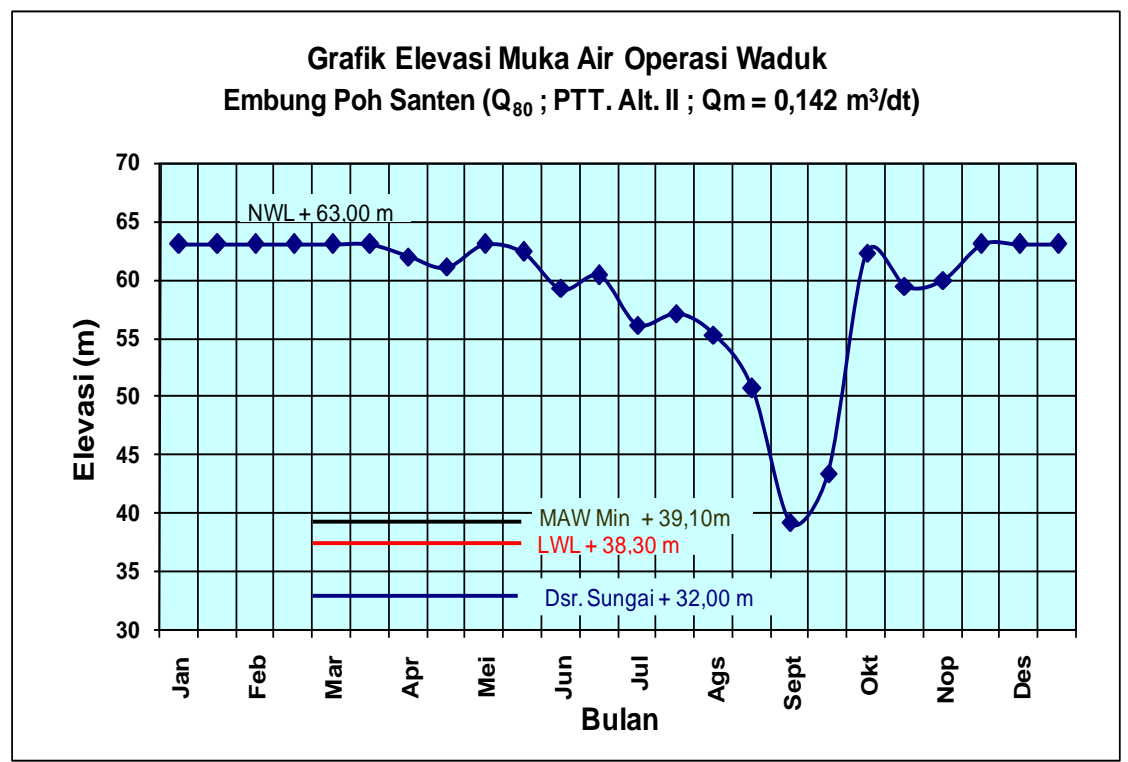

Gambar 6. Grafik Simulasi Elevasi Operasi Waduk

\section{DIMENSI HIDRAULIKA}

\section{A. Terowongan Pengelak}

Saluran pengelak direncanakan dengan konstruksi beton bertulang dengan dimensi sebagai berikut :

$\begin{array}{ll}\text { Debit rencana } & : 122,926 \mathrm{~m}^{3} / \mathrm{dt} \\ \text { Bentuk } & : \text { Segiempat } \\ \text { Dimensi } & : 2 \times 2 \times 2,5 \mathrm{~m} \\ \text { El. Inlet } & :+36,00 \mathrm{~m} \\ \text { El. Outlet } & :+31,00 \mathrm{~m} \\ \text { Panjang } & : 180,00 \mathrm{~m} \\ \text { Kemiringan } & : 0,02778\end{array}$

B. Bangunan Pengambilan

Dari analisis hidraulika ditetapkan dimensi teknis bangunan pengambilan sebagai berikut:

$\begin{array}{ll}\text { Debit rencana } & : 0,60 \mathrm{~m}^{3} / \mathrm{dt} \\ \text { Irigasi } & : \text { Qir }=0,405 \mathrm{~m}^{3} / \mathrm{dt} \\ \text { Air minum } & : \text { Qm }=0,142 \mathrm{~m} 3 / \mathrm{d} \\ \text { Tipe } & : \text { Drop Inlet } \\ \text { Bentuk } & : \text { Segiempat } \\ \text { Konstruksi } & : \text { Beton Bertulang } \\ \text { Elevasi Inlet } & :+38,30 \mathrm{~m} \\ \varnothing \text { Pipa Utama } & : 75,00 \mathrm{~cm} \text { (irigasi \& } \\ \text { Ø Pipa 2 } & \text { air minum) } \\ \text { Bangunan Pelimpah }\end{array}$

INERSIA, Vol. XVI No. 2, Desember 2020
Dari perhitungan hidraulika aliran diperoleh dimensi pelimpah sebagai berikut :

1) Bendung Pelimpah

Tipe

: Side Channel

Lebar

El. Mercu $:+63,00 \mathrm{~m}$

Kemiringan : $3: 1$ (muka)

2) Saluran Samping

$: 1: 0,667$ (hilir)

Lebar

: 8,00 m (hulu)

El. Dasar $\quad:+59,30 \mathrm{~m}$ (hulu)

: $+56,00 \mathrm{~m}$ (hilir)

Kemiringan : 0,00753

3) Saluran Transisi

Lebar

Panjang

$14,00 \mathrm{~m}$

El. Dasar

$41,50 \mathrm{~m}$

$:+56,40 \mathrm{~m}$ (hilir)

Kemiringan $: 0,00241$

Ambang : :0,50 m

4) Saluran Peluncur

Lebar

: 14,00 m (hulu)

Panjang $\quad: 54,50 \mathrm{~m}$

Kemiringan : :0,346

5) Peredam energi

Tipe

: Slotted

Bucket

Lebar $\quad: 14,00 \mathrm{~m}$ 


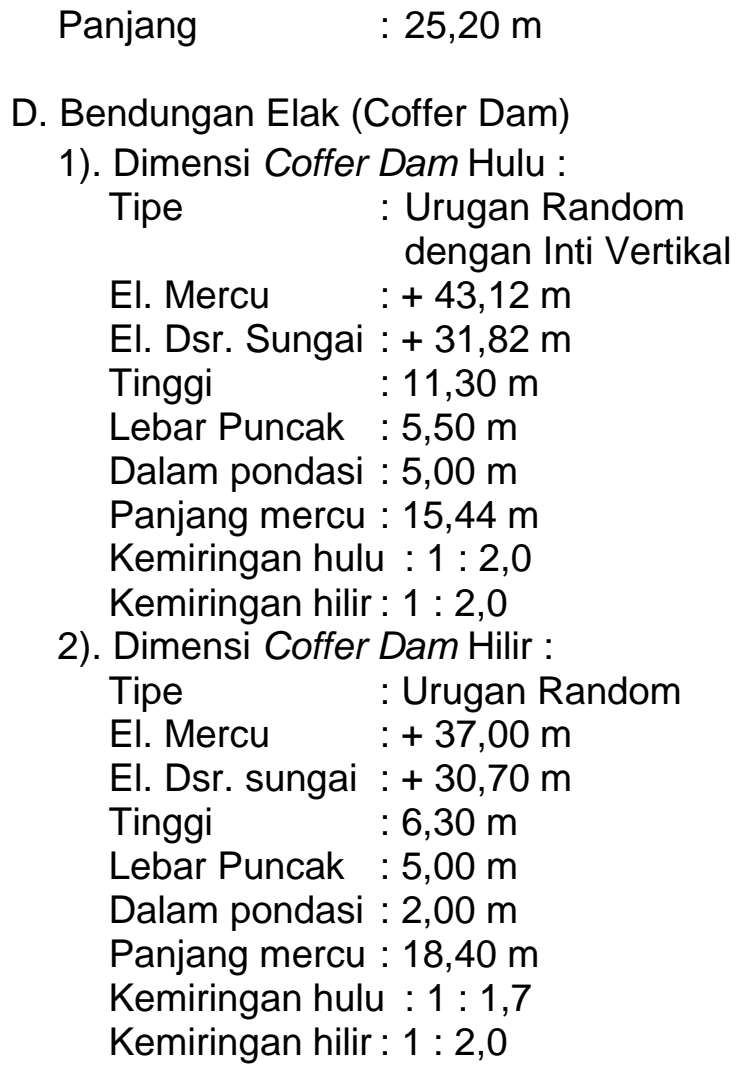
Tipe : Urugan Random
El. Mercu $:+37,00 \mathrm{~m}$
El. Dsr. sungai $:+30,70 \mathrm{~m}$
Tinggi $\quad: 6,30 \mathrm{~m}$
Lebar Puncak : $5,00 \mathrm{~m}$
Dalam pondasi : $2,00 \mathrm{~m}$
Panjang mercu : 18,40 m
Kemiringan hulu $: 1: 1,7$
Kemiringan hilir : $1: 2,0$

E. Bendungan Utama (Main Dam)

Sesuai dengan analisis hidraulika dan penelusuran banjir pada Q PMF dapat diperloleh dimensi tubuh Bendungan dan coffer dam dari Bendungan Poh Santen sebagai berikut :

$\begin{array}{ll}\text { Tipe } & \begin{array}{l}\text { : Urugan } \\ \text { dengan Inti Vertikal }\end{array} \\ \text { El. Mercu } & :+67,00 \mathrm{~m} \\ \text { El. Dsr. Sungai } & :+32,00 \mathrm{~m} \\ \text { Tinggi } & : 35,00 \mathrm{~m} \\ \text { Lebar Puncak } & : 9,0 \mathrm{~m} \\ \text { Dalam pondasi } & : 6,0 \mathrm{~m} \\ \text { Panjang mercu } & : 107,9 \mathrm{~m} \\ \text { Kemiringan hulu } & : 1: 2 \\ \text { Kemiringan hilir } & : 1: 2\end{array}$

F. Karakteristik Tampungan Waduk Karakteristik tampungan merupakan ciri-ciri batasan tampungan yang terdapat dalam penampang tampungan waduk.

Karakteristik waduk dapat dirinci sebagai berikut:

LWL (Low Water Level) $\quad$ : + 38,30 m
NWL (Normal Water Level) : +

HWL (High Water Level) : + 64,93 m

Vol. Tampungan Mati $: 12,775 \times 10^{3}$ $\mathrm{m}^{3}$

Vol. Tampungan Efektif $\quad: 1.259,637 x$ $10^{3} \mathrm{~m}^{3}$

Vol. Tampungan Total $\quad: 1.272,412 \mathrm{x}$ $10^{3} \mathrm{~m}^{3}$

\section{ANALISIS KELAYAKAN}

Berdasarkan harga satuan yang berlaku dan mengacu pada kurs dolar Rp. 12.000,/dolar, maka total biaya pembangunan bendungan Poh Santen sebesar Rp. $68.242 .781 .880,00,-(68,243$ milyar rupiah dengan lama pembangunan 3 tahun.

Manfaat langsung yang diperoleh secara langsung sebagai akibat dilaksanakannya proyek adalah bertambahnya pasokan air baku untuk kepentingan irigasi dan bertambahnya pasokan air bersih untuk masyarakat di sekitar proyek dan pada bagian hilirnya.

\section{1). Peningkatan Produksi Pertanian}

Pelayanan untuk irigasi hanya akan memberikan manfaat berupa meningkatnya intensitas tanam yang dari kondisi semula tidak lebih dari 200 persen menjadi antara 260 hingga 280 persen.

Produksi pertanian petani diestimasi ratarata mencapai 0,5 ton per ha untuk padi dari rataan 5,0 to /ha menjadi 5,5 ton/ha dan 0,4 ton per ha untuk tanaman palawija (kedelai) dari rataan 2,2 ton/ha menjadi 2,6 ton/ha.

Peningkatan intensitas tanam dengan pola tanam padi-padi/ palawija-palawija/ bero diestimasi terjadi hingga 60-80 persen dari kondisi mula-mula 200 persen dengan pola tanam padi-palawija-bero.

2). Ketersediaan Air Bersih 
Feasibility Study ... (Ketut/ hal 179-190)

Manfaat langsung pasokan air bersih dari

Bendungan Poh Santen dapat memberikan

pasokan air baku sebesar 142 liter/det atau $0,142 \mathrm{~m}^{3}$.

Tabel 3. Rencana Anggaran Biaya (RAB)

\begin{tabular}{|c|c|c|c|c|c|}
\hline \multirow{2}{*}{ No } & \multirow{2}{*}{ Kegiatan } & \multirow{2}{*}{$\begin{array}{l}\text { Biaya (000 } \\
\text { (Rp.) }\end{array}$} & \multicolumn{3}{|c|}{ Jadwal Pelaksanaan Tahun ke- } \\
\hline & & & 1 & 2 & 3 \\
\hline 1 & $\begin{array}{l}\text { Mobilasi } \\
\text { Demobilisasi }\end{array}$ & $40.000,00$ & $40.000,00$ & - & - \\
\hline 2 & Copper Dam & $7.938 .140,90$ & $6.350 .512,72$ & $1.587 .628,18$ & - \\
\hline 3 & $\begin{array}{l}\text { Bangunan } \\
\text { Utama }\end{array}$ & $3.567 .668,26$ & $356.766,83$ & $1.605 .450,72$ & $1.605 .450,72$ \\
\hline \multirow[t]{3}{*}{4} & $\begin{array}{l}\text { Bangunan } \\
\text { Pendukung }\end{array}$ & & & & \\
\hline & -Pelimpah & $33.655 .410,06$ & $11.779 .393,52$ & $21.876 .016,54$ & - \\
\hline & $\begin{array}{l}\text { Samping } \\
\text {-Intake }\end{array}$ & $13.882 .940,23$ & - & $2.776 .588,05$ & 11.106.352,18 \\
\hline \multirow[t]{6}{*}{5} & $\begin{array}{l}\text { Bangunan } \\
\text { Lain-lain }\end{array}$ & - & - & - & - \\
\hline & JUMLAH & $59.084 .659,44$ & $18.527 .173,52$ & $27.845 .683,48$ & $12.711 .802,90$ \\
\hline & $\begin{array}{l}\text { Konsultan } \\
\text { Fee (5\%) }\end{array}$ & $2.954 .232,97$ & $926.358,65$ & $1.392 .284,17$ & $635.590,15$ \\
\hline & $\begin{array}{l}\text { Jumlah } \\
\text { setelah Fee }\end{array}$ & $62.038 .892,42$ & $19.453 .531,72$ & 29.237.967,65 & 13.347.393,05 \\
\hline & PPN (10 \%) & $6.203 .889,24$ & $1.945 .353,17$ & 2.923.796,77 & $1.334 .739,30$ \\
\hline & JUMLAH & $68.242 .781,66$ & $21.398 .884,89$ & $32.161 .764,42$ & $14.682 .132,35$ \\
\hline
\end{tabular}

Pasokan air baku ini merupakan bahan baku dari air bersih yang dapat disuplaikan oleh PDAM kepada masyarakat setelah melalui proses pengolahan sebagaimana mestinya. Analisis atas harga ekonomis air baku dari bangunan pelepasan pada outlet Bendungan dalam hal ini ditetapkan seharga $\mathrm{Rp} 1.000,00$ per meter kubik. Artinya, jika untuk pengolahan menjadi air bersih, masih diperlukan kegiatan instalasi jaringan dan water treatment plant (WTP) sehingga akan mengubah harga ekonomi air menjadi lebih tinggi. Dalam hal ini kajian hanya dibatasi hingga produk akhir berupa air baku yang dapat disadap dari outlet Bendungan.

Secara umum, semua dampak berantai mengarah kepada terjadinya peningkatan kegiatan ekonomi kawasan yang dalam kajian ini diasumsikan dapat mencapai nilai sebesar 30 persen dari nilai manfaat langsung.

Dengan kondisi biaya dan manfaat yang telah diuraikan di atas, setelah dilakukan analisa ekonomi dengan metode Economic Rate of Return (IRR), Benefit Cost Ratio (BCR) dan Net Present Value (NPV) serta sensitivitasnya apabila terjadi kenaikan biaya sebesar $10 \%$, penurunan nilai manfaat sebesar $10 \%$ serta kemunduran penyelesaian pekerjaan selama 2 tahun, diperoleh hasil sebagai berikut :

Tabel 4. Perhitungan Analisis Kelayakan

\begin{tabular}{lcccc}
\hline $\begin{array}{l}\text { Paramet } \\
\text { er }\end{array}$ & Normal & $\begin{array}{l}\text { Konstr+ } \\
10 \%\end{array}$ & $\begin{array}{l}\text { Benefit+ } \\
10 \%\end{array}$ & $\begin{array}{l}\text { Konst } \\
+2 \text { th }\end{array}$ \\
\hline IRR $(\%)$ & 13.66 & 12.52 & 12.39 & 12.17
\end{tabular}




\begin{tabular}{|c|c|c|c|c|}
\hline $\begin{array}{l}\text { BCR } \\
(\mathrm{i}=12 \%)\end{array}$ & 1.15 & 1.04 & 1.03 & 1.01 \\
\hline $\begin{array}{l}\text { NPV } \\
(\mathrm{i}=12 \%)\end{array}$ & $\begin{array}{l}8,043 . \\
52 \text { juta }\end{array}$ & $\begin{array}{c}2,465.7 \\
3 \text { juta }\end{array}$ & $\begin{array}{c}1,662.28 \\
\text { juta }\end{array}$ & $\begin{array}{l}677.7 \\
4 \text { juta }\end{array}$ \\
\hline
\end{tabular}

Dinilai dari kelayakan secara ekonomis, berdasarkan kriteria NPV, BCA dan IRR, rencana pembangunan Bendungan Poh Santen dapat dilaksanakan pada asumsiasumsi yang dipakai, dengan nilai ekonomis manfaat rata-rata pertahun sebesar $\mathrm{Rp}$ $10.903,66$ juta. Dari beberapa alternatif sensitifitas, perubahan kondisi biaya dan manfaat yang melebihi 10 persen sangat sensitif terhadap kelayakan ekonomi rencana pembangunan. Oleh karena itu faktor perubahan kondisi proyek dari sisi kemungkinan peningkatan biaya dan menurunnya nilai manfaat ini harus dikendalikan secara cermat dan hati-hati.

\section{SIMPULAN}

Secara keseluruhan dari kajian perencanaan teknis dan analisis kelayakan ekonomi dari Bendungan Poh Santen dapat diajukan rekomendasi sebagai berikut, dari hasil analisis kelayakan ekonomi yang telah dilakukan, maka Bendungan Poh Santen dapat dinyatakan layak secara ekonomi dan dapat dilanjutkan untuk detail desain.

\section{DAFTAR RUJUKAN}

Bali Irrigation Project. 1981. Feasibility Study Part 2, 35 Subak Improvement Schemes A Text. Milano-Seoul: ELCADC.

Departemen Pekerjaan Umum. 1986. Standar Perencanaan Bangunan Utama (KP-01; KP-06). Bandung: CV. Galang Persada.
DPU. 1994. Pedoman Kriteria Desain Bendungan Kecil Untuk Daerah Semi Kering di Indonesia. Jakarta: Pusat Penelitian dan Pengembangan Pengairan.

Pratama, G. N. I. P. P., \& Najihan, H. F. (2020, September). The Effect of Beach Sands to Replacement of Fine Aggregate with Addition Filler of Ash Cane on the Asphalt Mixture on Marshall Characteristics. In Journal of Physics: Conference Series (Vol. 1625, No. 1, p. 012032). IOP Publishing.

Pratama, G. N. I. P., \& Sumarjo, H. (2018). Aksesibilitas Tata Letak Elevator Penumpang Gedung Kantor Pusat Layanan Terpadu (KPLT) Fakultas Teknik UNY. INformasi dan Ekspose hasil Riset Teknik Slpil dan Arsitektur, 14(1), 26-35.

Sri Harto. 1990. Dasar-Dasar Hidrologi, Yogyakarta: PAU-UGM.

Soemarto, CD. 1987. Hidrologi Teknik. Surabaya: Erlangga.

Sosrodarsono, Suyono, dkk. 1981. Bendungan Tipe Urugan. Jakarta: PT. Pradnya Paramita.

Sudjarwadi. 1987. Dasar-Dasar Praktek Irigasi. Yogyakarta: PAU-UGM.

Imam Subarkah. 1980. Hidrologi Untuk Perencanaan Bangunan Air. Bandung: Idea Dharma. 